\title{
Intercultural Translation and Communication
}

\author{
Lorena Sadiku Manaj
}

\section{Abstract}

The accuracy of translation and interpretation in intercultural communication is a primary element in the exchange of messages between two or more cultures. When it comes to precision in translation, it is imperative to put in the foreground the precision of finding the equivalence or correspondence appropriate to the communication of two different identities. That precision is entirely in the hands of the translator, but not only. Accurate translation is related to the role of translator in this communication, but also the recognition of jogging elements, as well as the social context in which the process takes place. It is well known that intercultural communication has been achieved through translation science, as it is clear that without this science intercultural exchanges could not happen. There is no way to get used to all the languages of the world. Since the creation of human life, various verbal and nonverbal interpretations between different communities had to be communicated. Intercultural communication relies heavily on translation and interpretation, which are two very important tools for creating a bridge of meaning-crossing, from one language to another, and from one culture to another. Translation is one of the most ancient linguistic phenomena. It was seen as the necessary solution that brought the great number of languages around the world at a time when mankind had just started extending widely to the planet called Earth. Translation has a special merit in communicating between two speakers who speak different languages and have different cultures. Merit relates to the exchange of words that carry the meaning and accurate transmission of the message between two interlocutors or between two different identities with unmatched tradition, culture and habits. In intercultural communication, during the translation process, translators are left free to choose words to describe the concepts from source language to sign language, but this free hand is allowed only by being faithful to the meaning. An important role plays a social context as the interpreter should be attentive to distinguish which culture is being translated and is always ready to find the right linguistic and cultural parameters for the sole purpose of realizing communication. The work of an interpreter can not be done by anyone who knows two languages. The interpreter should be a good connoisseur of the language and culture of the source language and the sign language. Also, the interpreter must necessarily be a very good connoisseur of the social context, which translates or interprets. In intercultural communication, the work of an interpreter can not be left to linguistic equivalence alone, as it is highly riskful to convey the meaningful message. The sender transmits signals to the receiver. For a man who does not know the language - the source of the message, these signals find no sense, so it is imperative for the interpreter to intervene, who, besides being able to embody them, makes meaningful sense to the recipient of the message. How does he do this? Of course, finding the correct verbal and nonverbal parameters as well as necessarily calculating the time or social context in which the translation takes place. Given all the above elements, the interpreter should always be keen to achieve an accomplished communication. He should have a very good knowledge of the language and culture of the source language and quite well the language and culture of the sign language. You should also know the social period or context for which you are translating well. You can not overlook the inner state or curiosity of the interpreter himself.

Keywords: Intercultural Translation and Communication.

\section{Introduction}

\section{How do you find the right word at the right moment?}

Of course, it is not a major difficulty for a professional translator, but in different situations, difficulties can be made even possible or at a high level. This usually happens through cultural translations of the traditions or customs of a people or the 
daily or popular jargon of a certain identity. An example of the correct translation of a social reality in Albania is eating a basketball bag made by many Albanians during their long journeys. How can you explain to an alien, for example, that in Albania it has become good that when people leave for holidays in the south, at some stops along the way, stop eating locusts and pilafs? In folk culture or let's call it in the tradition of the current social context of Albanians, eating a few pupae pans is indispensable for gastric gathering so that you do not feel the mixture over a long journey. Can a Frenchman understand this, whose morning over a long journey is just a croissant and a glass of milk? The aforementioned situation is closely related to the fact that different realities are translated according to different situations. Of course, an interpreter should translate everything.

There is no doubt that we are living in times of great change. As we prepare teachers or students, we are aware of many changes taking place at the global level. Population shifting continues to happen all over the world, bringing in contact intercultural dialogue between groups who speak different languages and carry different cultures. This change does not affect only sectors of society, industry, health, politics or business, but also education. In different parts of Europe just like anywhere else in the world, school curriculum designers include intercultural objectives in school curricula and teachers find themselves facing the challenge of promoting and supporting the acquisition of intercultural competence through teaching. This is true for subject teachers but mostly for those of foreign languages. Foreign Language Teaching is intercultural in essence. Entering a foreign language into a classroom means connecting students with a world that is different from their world. Thus, nowadays it is expected to all foreign language teachers take advantage of this potential and encourage empowerment intercultural competence among students and their students. Intercultural competence is the degree to which a person is able to exchange information efficiently and appropriately to individuals who belong to adifferent crop. People have different ways of communicating with individuals who are remodeling of a different culture. This makes the intercultural process a difficult process. Purpose of whether expressed or not, of many researches in the field of intercultural communication is the improvement of intercultural competence in individuals. One of the most important competency barriers intercultural is ethnocentrism. Intercultural contact turns individuals into ethnocentric, prejudicial and discriminatory. Even when we are aware of the barriers they make particularly difficult intercultural communication, we can attribute it erroneously other people's problems and do not focus on our abilities or the lack of these skills. Misunderstandings are equally likely to be created by intercultural contacts as well understandings.

The objective of teaching foreign languages is no longer defined by the appropriation of communication competence in a foreign language. Teachers nowadays are required to teach students and students the intercultural communication competence. Being able to cope with intercultural experiences requires that a person possess a range competencies and intercultural characteristics. These powers and features are identified as a desire to engage in foreign culture, selfawareness and the ability to see oneself from an external point of view, the ability to see the world through the eyes of others, the ability to face the most insecure, the ability to acting as a cultural mediator, and the ability to consciously use the skills of learning the culture and to read the cultural context. Given the above, the article will focus first on a general theoretical overview on the importance of communicative and intercultural competences, various interpretations of the concepts as well as the way of passing and acquiring intercultural competence in English language learning. This competence is seen today as a modern trend in foreign language didactics and as one of the most important in the field of education, aiming at a multi-dimensional development of the individual's personality. First of all there are some of them important methods and exercises such as critical situations, role playing, simulations, which assist in the transference of intercultural competence develop this competence and decide students in real intercultural situations. Then examples of other methods will be given, such as laboratory learning, virtual realities, reflective dialogue, use of fictitious texts, the use of books, virtual classes, and learning through electronic media - all these show concrete aspects and awaken the interest of not only students but also teachers who are looking for ideas to promote the development of intercultural competence. To do it this will be even more clear proposals, examples and concrete exercises as well as instruments didactics to mediate and convey intercultural elements that help teachers for the organization of the lesson, but also the students to be able to communicate and interaction during different intercultural situations. An important part of the paper will be the collection of empirical data related to the role of teachers in intercultural learning of the English language, analyzing these data and extracting them and making conclusions and recommendations.

\section{What is culture?}

We encounter the notion of "culture" in diverse ways, in different contexts, as well as in diverse meanings and definitions. But what is meant by "culture"? It is about so-called " culture" such as theater, literature, architecture, etc., or the word is 
for everyday culture, for example. How we are nourished, how we fix the house and how to dress, how the women and men are greeted here, etc .; or with culture do we understand our traditions, rituals and customs? Culture is undoubtedly an integral part of our life and society. Also worthy of note is that with the phenomenon "culture" many scientists and personalities have taken over. Based on this, we can assert that "culture" is a complicated and manifold notion, since it itself is also cultural. Word culture implies important and countless aspects of life, making them an inseparable part of it. For most anthropologists, culture includes learned behaviors, beliefs, views, values, and ideals as characteristics of a particular society. It can therefore be said that each of us is born into a complex culture, which exerts a great influence throughout our lives. Culture has to do with the lifestyle of a society, and it includes not only the aspects that are considered more desirable in society, but mostly the everyday activities of everyday life. Suffice it to mention here the example of playing piano or reading the works of Kadare or another author. In this case, social science scientists would only consider elements of what is called general culture. But if we were to talk about culture as a whole, then we would recognize that culture also includes human activities, such as clothing, eating and drinking, washing clothes, driving events, etc. Uncultured society is said to have no, as there are, and uncultured individuals. So we agree with the opinion that every society has a culture, however simple it is and as a result each individual owns a culture, so it is cultured, being a member of a particular society. Culture is taught and adopted by being transmitted mainly through language. The first definition of the concept of culture is found in 1871, given by anthropologist Edward Taylor. In its definition, it is noted that the concept of "culture" includes knowledge, belief, art, law, morals, customs, as well as any other man-made ability and norm as a member of a society. It can be said that, from this point of view, the concept of culture is clear and understandable. But would there be any definitions that are so comprehensive, clear or would they have a more modern orientation? Would there be numerous definitions? It is worth mentioning that since then, the definitions have been numerous. Thus, in 1950, A. L. Kroeber and Clyde Kluckhohn collected from the literature about 100 definitions of culture. In all these definitions there is a clear division of behavior on the one hand, and the abstract values, beliefs and perceptions of the world, on the other. If we would say in other words, we would say that culture is a complex of values and beliefs people use to explain and create new behaviors. Although it is a word of frequent and frequent use, it is not always clear what it means. Like many other notions of this kind, "culture" is also meaningful and its meaning varies in context and usage. For this reason, there is no talk of a homogeneous and general definition of culture.

Thus, according to cultural and social anthropology, which deals mainly with the research of "Cultures" count over 500 definitions of culture. As mentioned above, culture is a difficult notion to define, as there is no single definition accepted by everyone. For this very reason, in this paper we will mainly dwell on those definitions, which are important to our topic. Initially, it is important to know the etymology of the word culture, from which language has its source and what its prime meaning is. The word culture comes from Latin culture ("work, plowing of the earth"; the body (of the soul) ", which is related to the cholera (" cultivate "," cater ") and generally indicate the way people build their lives together with what they have been thinking and achieving.

\section{Intercultural and interculturality}

The main aspects of intercultural studies include issues of intercultural learning in foreign language learning. But before addressing the aspect of intercultural learning, it is important and necessary to clarify and explain the notion of "intercultural" as a broad and highly controversial notion. What is understood by this notion can be seen in different ways according to the scientific disciplines, which we have seen above in explaining the notion of "culture". Generally speaking, aspects of "interculturality" or "intercultural" are understood as a classic example or as a personification of communication between people of different cultures. According to Neuland, communication between speakers of different cultures is always meaningful and this is not only in the context of increasingly growing internationalization of politics, economy, education and culture, but also in teaching a language. Of course, not all the definitions can be addressed in this paper, but those aspects, which have a special significance in learning English for foreigners. The "intercultural" notion is widely used since the mid-1970s and early 1980s, in a very large number of combined definitions, more or less related to teaching and learning of foreign languages. Initially, this notion came out as a thematic word in the field of pedagogy and later in the didactics of foreign languages. It implies the necessary learning that leads to a better understanding of the respective culture as a different culture, alien and its own culture, as we live in a society where different cultures meet. It is about developing the readiness and the ability to be sensitized to the views and ways of others' behavior, to understand them, to tolerate and learn from it something about personal behavior. Concerning this is understood the processes of exchange between cultures, or more specifically: between persons and groups with different cultural history and traditions. 
From the point of view, we think that Latin prefixes inter- mean exactly "between two or more entities, with each other, mutually." So let's note that in relation to "interculturality" it is a "between (them)" .Interculturality unfolds as a theoretical model of how to behave in different situations of cultural meetings in which cultures can not be seen as biased, but as open systems of rules, which act in mutual respect and exchange with each other.

Only after the collapse of the communist system, after the 90s, the term "intercultural" and "intercultural" began to be talked about, although it did not really mean the same thing, which was supposed to be spoken in the western Europe. This notion began to be used almost for every relationship between foreign countries and their countries, as well as everything related to foreign culture, and was described as "intercultural". Thus, the fact that interculturality is also intriguing was also ignored. But we can say that after the overthrow of the political system after the 1990s, something began to change, as teachers, but not only, began to encounter this notion abroad; so they began to get acquainted with his meaning, then introduced in Albania. The result was extremely positive, as Albanians were later able to explain different intercultural situations as well as the very meaning of the notion. They also began to rely on the notion of "cooperation" between foreign cultures, of course in a broader sense. This view is not wrong, because everywhere, where different cultures meet, we are dealing with intercultural situations.

We think that there was no ideological or political reason for delaying the use of interculturality. In France, for example, in the years of communism they have studied and specialize in foreign language teachers but they have not approached the intercultural concept.

\section{Communication and Intercultural Competence - Intercultural Communication}

Communication is a common and well-known part of our lives that we often do not we pay attention to the importance. Moreover, we often participate in the communication process only as senders and recipients of information without being aware that we are dealing with a complex process, which itself contains many interconnected steps with each other. Human society is built and exists precisely thanks to the human ability for communication. There are many tools that serve to communicate between people: gestures, screams, different signals, but the main tool is nested speech etc. Knowing how to communicate with other people is very important, but on the other hand you have the ability to be understandable about what you intend to say to them is a circumstance that facilitates relationships with them, thus avoiding misunderstandings, disagreements or conflicts. On a few occasions in our daily lives we have noticed that the cause of the great and sometimes insoluble conflicts may have been a mistaken word, not in the right place, as well as badly understood or heard. Also, we may often have felt badly when someone has talked to us seriously or did not understand us properly. Precisely regarding the correct use of the word, Mark Twain would write in his statement that "the difference between the word correctly and what is almost correct is the difference between the light of lightning and the light of the candle". For this, the experience of everyday life has shown that finding the right communication with everyone is difficult.

- First, we need to understand that not everyone thinks and desires the same. For example, likes read, another enjoys hiking in nature.

- Second, we talk to each other about different topics. If we do not like the theme, of course we can retreat, but that does not make us feel good.

- Third, not everyone is tolerant and uncomplicated and understands each other as it is without pre-ordination. To handle and resolve a dispute or conflict, it is imperative to have effective communication. The question should not be asked, "What is the definition of communication?" Or "What is communication?". The answer to this question can not be the same from everyone. Anyone from us would have a different answer. The most appropriate question would be, "What do we understand by communication and what do we want to say, express and convey by word?" Indeed, all the human relationship displayed as human relationships with each other, the human being with nature or the human being, is in fact in essence an infinite number of communications. Therefore, we find communication treatments in the most ancient thinkers, and therefore there is also a set of communication definitions.

Communication is not only an integral part of our daily life, but also an element of important for any form of coexistence among people. Communication involves everyone; it appears in all human situations. Given this, the fact is not surprising, why there are so many communication theories, and why defining the notion of "communication" is not easy at all, but an extremely complex issue. 
The words communicate, communication are the source of the communicative Latin verb and are used in many languages, taking appropriate forms according to their phonetic-grammatical structure. In Latin this verb has the following meanings: 1. make joint; 2. participate, to something with someone; 3. interlock, add. (HenrikLacaj - FilipFishta, Latin-Albanian Dictionary Tiranë, 1966, s.v.). In the "Albanian Dictionary of today "(2002) 48, are given two meanings of the word" communication ": 1) action and state by verbs communicate, communicate (eg communication tool); 2) short notice, announcement (what is transmitted). But what does it mean to communicate? Like many other words in a language, the verb communication or the name of the communication that comes from it are words of great significance.

From this we can say that we face a difficulty defining the notion "com- muny". In the most general sense, this notion is used for any relationship in relationships. So with communication we understand, firstly, putting into relationships of human minds. The notion "communication" can be defined as a process by which the communicator's internal discourse is transmitted to others. In this case we are dealing with a kind of process called human communication or oral communication. So communicating means communicating the information you have in mind.

It is in this process that we have the giver and recipient, namely the communicator, the one that starts communication and convey to others: knowledge, memories, images, trials, desires, feelings, etc., as a variety of things.

Research on intercultural communication is relatively new and started exactly when language science was being tackled not only with the semantic and syntax of the language, but also with the pragmatic one. The term "intercultural" includes all the phenomena that arise from contact between different cultures, but which do not always have a communicative dimension

It distinguishes four dimensions, namely: individualism - collectivism, power of distance, avoidance of insecurity and feminism / masculism. The first dimension (individualism and collectivism) can not be understood politically, but in anthropological terms. Individualist cultures assume that everyone in the first place cares for themselves. Quite differently happens in collective cultures.

In such a culture, everyone belongs to a certain group, who you must remain faithful to power of distance as a particular aspect of culture implies acceptance within a society of this distance from the weak, calling it quite normal. But avoiding uncertainty determines to what points of a culture show nervousness in situations that are unclear and unexpected. Given this, they try to avoid such situations by setting behavioral rules and confidence in absolute truth. Cultures, which have a significant avoidance of uncertainty, are more active, aggressive, sensitive, intolerant and in search of security. While cultures which try to avoid the least uncertainty, are less aggressive, cold, relatively tolerant and accept personal risks. The last dimension relates to feminist and machinist cultures. The masculine cultures emphasize the prohibition of men by women and the superiority of men. Men should be ambitious and competitive. They should also aim to be successful. It is quite different in cultures feminist, where the differences between men and women are not clear enough. What is highlighted by scholars, there are other variants of quality of life, namely social relationships as well care for the weakest. Basically any communication situation carries a risk on its own. This happens if the speaker has no knowledge of cultural good, in order to avoid the dangers. For Marsh (1993) 102 are extremely important situations in intercultural communication. It introduces the concept of "situational adaptability / adaptability to the situation ". In his opinion it is a great advantage that the science of different academic ones, such as anthropology, sociolinguistics, etc., have approached each other as far as this topic is concerned. Different views have shown that if a person is in acertain situation, there are many different, psychological, social, and biological factors that influence this process.

There are two ways to look at intercultural communication, namely the "maximalist and minimalistic approach / maximum and minimum approach". Blommaert's (1988) maximum approach 107 supports the view that a person's culture always determines how the latter can interact with others.

According to Blommaert, this view is hidden, so it is not straightforward, as it presents an unchanged view of culture and its representatives.

If solutions to any problems related to intercultural communication will be sought, attention will focus on misunderstandings, completely forgetting the most successful communication process. People try to adapt not only to situations but also to interlocutors during communication. Thus, successes or failures are always the result of action in a given situation, but also part of human goals. One of the most common reasons for intercultural misunderstanding is the different use of mechanisms that promote communication. Such mechanisms include, for example, the right to speak, the mutual control of "listeners" 
through the addition of speech, listeners' passages, and through particles such as "hm". However, many of the communication situations are developing nonverbally, which is what it does even more complicated intercultural communication.

But what do they really change? This question is it is difficult to give an answer, as we would easily create cliché and stereotype. Everyone has created for other countries, their people and cultures their imaginations and ideas and perceptions that they can to be general, but also detailed. Perceptions are closely related with each other. They not only exist in our minds, but are also extremely subjective.

\section{Intercultural communication in the curriculum}

Intercultural learning of foreign language develops student communication skills. He offers them knowledge and skills for language and its use and gives them the opportunity to develop knowledge about foreign cultures to better understand and respect these cultures. In this case attention focuses on European identity, multilingualism and the diversity of cultures. So students become more able to learn foreign language in the most autonomous way. They also understand, that in order to have a communicative competence, communication should be exercised in a continuous way, durable and versatile. Therefore foreign language is considered as a whole skills, knowledge, but also as a cultural whole. The learner should be able to communicate appropriately in a language and foreign culture. He should be able to evaluate his / her language skills in relation to objectives and identify its strengths and weaknesses. The words in collision conspiracy.Intercultural situational adaptability as a success factor.

Cultural and intercultural competences are part of important to foreign language learning. For this, intercultural orientation should be part of inseparable, such as listening, speaking, writing and reading. Culture and Interculturalism should be included in the curriculum, but not only. Each language book (method) of the language foreigners should be equipped with cultural and intercultural elements, such as textbooks, role playing,dialogues according to authentic situations etc.

As we have mentioned in the heading above, learning the culture is part of the teaching of each language alien. This enables students to make a real assessment as well and a cultural exchange with their peers. In this way, the students except the competences communicative, and cultural development, from which it is created and respect for other cultures. So communication in a foreign language also implies cultural training. It is important for cultural exchanges to be part of foreign language learning, as this motivates students to communicate as much as possible during conversations and discussions. In multicultural classes in which pupils and teachers belong to different cultures, these cultural conversations are naturally more varied. Anyone would have to show it in this case something from his culture, pointing to the changes, but also the similarities that exist between the cultures. In this area naturally arises the question of what happens in singlecultural classes? In such classroom students and / or teachers come from the same culture, which makes the situation extremely difficult. In such students rely on the teacher to understand the language being taught but also to get as much knowledge as possible about the culture of this language. If we would say what we said above in other words, we would point out that every foreign language teacher teaches students not only knowledge, but also culture. Since language and culture are inseparable, then culture must be part of it component of the foreign language program. About the relationship between language and culture have been written even Somavar, Porter \& Jain, who call the link between culture and communication inseparable. By calling culture as the foundation of communication, they show that culture takes care of continuity of communication.

\section{Intercultural competences}

Everyone has its own history, life and therefore its own culture. In other words, each individual has its own cultural affiliation, or its cultural identity. In the relationship between people, this has to do, on one hand, with the changes that exist between cultures, regions, continents, or countries, but not only. Differences and differences exist between companies and their departments, between groups and minorities, different social strata and classes, or members of the same family, as long as there is talk of different social values. These cultural changes are not only relevant to a proper interaction, but also for the development of personal competencies. If we want to present a summary of the concept of intercultural competence, we will come up with concluding that this is not easy at all. For decades it has been emphasized and accepted, that being fit in the intercultural aspect is extremely important for a more cohabitation successful in a diverse world. Possessing intercultural competence is more important to develop and maintain democratic societies. 
With a variety of meanings of this concept, the multiple views on related to this notion always have a positive impact on the process of understanding. Of course that besides the changes there is a range of common things. The notion of "intercultural competence" constitutes a modern concept, which has developed in half second century AD, as a result of massive migration and ever-growing globalization. About itmany researches have been conducted in various fields such as psychology, as well as foreign language, sociology, anthropology, cultural science, pedagogy, philosophy, linguistics and economic science. For each field the definition has its own characteristics. So for example, in language a clear distinction between intercultural competence and factual cultural knowledge.

For some scholars, intercultural competence has an important pragmatic part, namely increase tolerance to other cultures. The ability of speakers of different ages and gender to coexist in one society, peacefully and without mutual discrimination ". Because there are multiple views about communication competence, there are also different perceptions of intercultural competence. The following comparison of the selected definitions is intended to demonstrate the widespread use of this concept.

Intercultural knowledge, emotional dimensions (intercultural sensitivity) and dimensions connotative (acting ability in intercultural situations). All three of these powers allow us to have consider the concepts of perception, thinking, feeling and influence of foreign culture on our actions. It is also worth noting that all three of these dimensions are related with each other. Thus we can mention that the ratio of knowledge of intercultural processes is equally within the cognitive dimension. Elementary knowledge of cultural differences are not enough, as they fail to explain the processes of concrete interaction among the members of these cultures. So if we focus on the comparative views of cultures, we must also need to consider the interaction, as the latter best meets the first. The same we can also say about the emotional dimension, which is complemented by the connotative one. Ability to act in intercultural situations, which is seen as one of the basic goals in teaching foreign languages, plays an important role in intercultural learning of foreign languages. It is closely related to developing the student's identity towards intercultural learning. In such cases, experiences are restored intercultural personality of the competent person, creating the possibility of reviewing the stereotypes and prejudices and to learn something new. At the individual level, intercultural competences it is only an extension of interpersonal competence. To achieve intercultural competence, it is necessary adopting many factors: first, the recognition of the linguistic code, and the second, the recognition of the cultural environment as a basis for communication and awareness of personal behavior in relation to culture. Third, foreign culture and cultural expectation should be recognized and understood. Achieving intercultural competence representation represents an important process that extends throughout human life; this process should be started as early as possible and practiced in a consistent manner. Today intercultural competence is considered a modern trend in foreign language didactics and especially English. Intercultural competence is seen as one of the most important notions of the XXI century, also in the field of education, but also the main objective of intercultural learning in educational institutions.

So we can summarize that language and culture are an inseparable part and that learning a foreign language also means recognizing a certain culture. Knowledge of mother tongue culture, or as is known differently and in the first language, it is also a necessity for language teachers because otherwise we would have overestimated the parent culture and denigration of the culture of other nations. Learning a foreign language is inseparably linked to knowledge or learning of culture. But on the other hand, learning a foreign language or even mastering thatsemantic language, syntactic or pragmatic is not sufficient for an intercultural genuine dialogue. Very important is to know how to deal with and respond to our various intercultural behavior situations. Relying on the ideas that we have noted about intercultural concepts, examples studied, concrete case studies and collecting the opinions and views of teachers, can we draw the following conclusions:

-The term "communicative competence" is dealt with by many scholars as a competence which includes all forms of language communication. This competence is not simply about recognizing the structure language, but also with the meaning, possession and use of endless sentences in situations different backgrounds of everyday life using so and social experience,about the competence communicative has different interpretations. Here is shown particularly the interpretation that anthropologist Dell Hymes has given to communication skills. According to Hymes the competency communication is not only the grammatical knowledge of the speaker but also thepsycholinguistic, social and pragmatic knowledge.

-Intercultural communication is also defined as a process of exchange in which they are involved individuals of two or more cultures in different attractive situations. Naturally, the question arises, how much knowledge the interlocutor has in communication about the culture of the other. Although there are different views of what the intercultural competence 
implies, most researchers dealing with this concept are convinced that intercultural competences (defined as the ability to act in intercultural contexts) is transmitted to events and situations certain. This view seems credible if intercultural competence is not viewed as well self - sufficient and fully acquired ability, but as an integral part of a general ability to acting in different intercultural situations. The latter consists of partial competences, such as: individual, social, strategic, professional competencies, which find expansion in the intercultural context. Intercultural competence remains one of the most affected topics discussed, which is increasingly in the spotlight. Which of these competences to Partial individual is the most priority, it is depending on the relevant culture, the situation and everyone's interests. Because of these differences and different interests there can not be a single and general definition of intercultural competence. This chapter has had also as an objective to present the main concepts of intercultural competence and intercultural communication, different interpretations of these concepts and the acquisition and transmission of this competence in learning English in particular, but also of any foreign language in general. 